\title{
Variation in use of video assisted thoracic surgery in the United Kingdom
}

\author{
Artyom Sedrakyan, Jan van der Meulen, James Lewsey, Tom Treasure
}

\section{Introduction}

Video assisted thoracic surgery (VATS) is a minimally invasive technique for the diagnosis and treatment of lung and pleural disease. Thoracotomy is replaced by up to three small incisions from 0.5 to $2.0 \mathrm{~cm}$ long and well lit video images are displayed on large screens, allowing the surgeon, assistants, and students a view. ${ }^{1}$ Variation in the use of medical procedures cannot be fully explained by the prevalence of the disease in question or health characteristics of populations. The willingness of the surgeon to provide a procedure, rather than its appropriateness for the patient, may explain a substantial variation in practice. ${ }^{234}$

In our companion paper in this issue we systematically reviewed the evidence for VATS for pneumothorax surgery, minor resections, and lobectomy. ${ }^{5}$ Here we determine variation in the use of this procedure in UK practice.

\section{Participants, methods, and results}

From the register of the Society of Cardiothoracic Surgeons of Great Britain and Ireland (2000-2002) we extracted for the counts of patients operated on for pneumothorax, lobectomy, and sublobar (usually wedge) resections. Multilevel logistic regression was used to take account of the clustering of patients within centres (MlwiN statistical package, release 1.10.0007). We transformed the proportions of VATS versus thoracotomy for each hospital on to log odds scales and used the variance among hospitals as a measure of the variation in VATS use. We estimated the correlation between VATS use for pneumothorax and minor resection with the multilevel approach.

Pneumothorax surgery-2606 procedures were performed in 40 centres. VATS was used in 1485 (57\%) of these procedures. VATS use ranged from $0 \%$ to $100 \%$ (figure).

Minor resection -2691 procedures were performed in 39 centres. VATS was used in 1507 (56\%), with less variation compared with pneumothorax surgery.

Lobectomy-3879 lobectomies were performed in 40 hospitals. VATS was used in only six hospitals, with two hospitals accounting for over $60 \%$ of the use. As only $3 \%(\mathrm{n}=123)$ of lobectomies were performed by VATS in just $15 \%$ of units, further statistical analysis was not considered useful.

Variation between hospitals in VATS use for pneumothorax surgery was substantially larger than that for minor resection (variance in use on log odds scale 5.0 and 1.1 , respectively, $\mathrm{P}<0.001$ ). The correlation between use of VATS for pneumothorax surgery and minor resections was estimated to be $0.39(\mathrm{P}=0.04)$. Variation was not related to the total number of procedures that the units had carried out.

\section{What is already known on this topic}

Video assisted thoracic surgery is effective and is a less invasive treatment for pneumothorax than thoracotomy

\section{What this study adds}

In the United Kingdom adoption of video assisted thoracic surgery for pneumothorax ranges from none to $100 \%$

\section{Comment}

There is wide variation in the adoption of VATS in UK thoracic surgery. We believe this variation is more likely to be related to preferences of individual surgeons rather than the facilities available because the correlation between use of VATS for pneumothorax and minor resections is not strong. Although some variation may be related to differences in patients' characteristics, differences in case mix are unlikely to explain this large variation in practice. Given the evidence for VATS use in pneumothorax and minor lung resections ${ }^{5}$ the large variation in the implementation of this technology deserves reflection. The transition from a policy of full thoracotomy to the new technology takes retraining and practice, but those who have adopted VATS find that rather than being a compromise procedure, undertaken to spare the patient a thoracotomy and to reduce pain and bed days, it is a technically better approach. The surgeon operates in a comfortable position with an enhanced and well lit view of the operative field, which is seen equally well by everyone in the operating room. This greatly facilitates training and supervision.

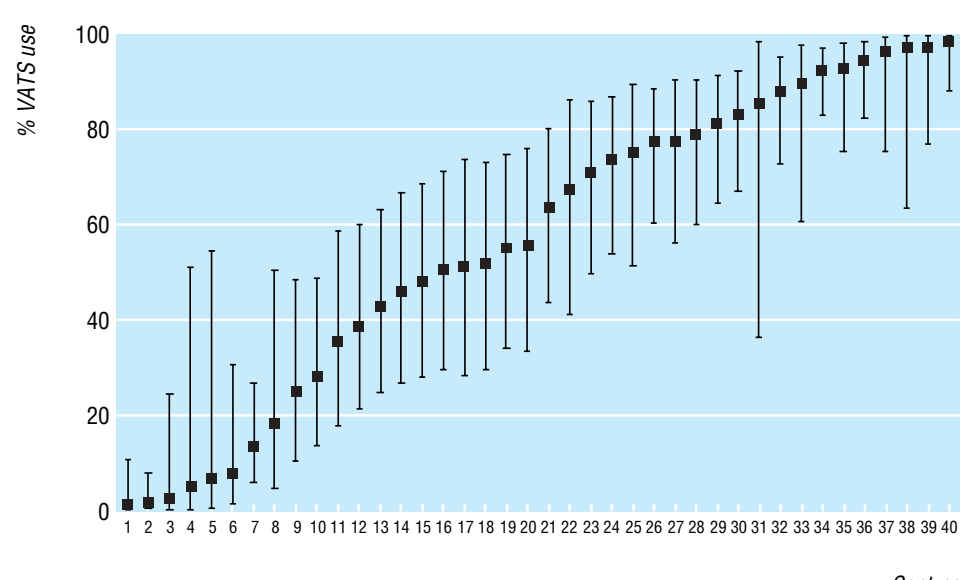

Variation between UK hospitals in use of VATS for pneumothorax. Centres are ranked by proportion of VATS use and vertical lines represent $95 \%$ confidence intervals
Health Services

Research Unit, Department of Public Health and Policy, London School of Hygiene and Tropical Medicine, London WC1E 7HT

Artyom Sedrakyan research scholar Jan van der Meulen senior lecturer

James Lewsey lecturer

Cardiothoracic Unit, Guy's Hospital, London SE1 9RT

Tom Treasure

professor of

cardiothoracic surgery

Correspondence to: T Treasure

tom.treasure@gstt. sthames.nhs.uk

BMJ 2004;329:1011-2 honorary lecturer and 
Data were voluntarily provided by members of the Society of Cardiothoracic Surgeons of Great Britain and Ireland. Tom Treasure is responsible to the society for the collection and collation of these data and has a mandate from the society's annual general meeting of its members to disseminate information based on the data.

Contributors: AS, TT, and JvdM were responsible for study concept and design. TT and AS were responsible for acquisition of the data and administrative, technical, or material support. AS and JL analysed the data and provided statistical expertise. AS drafted and TT finalised the manuscript. All authors interpreted the results and critically revised the manuscript for important intellectual content. TT and AS are guarantors.

Funding: There was no specific funding for this study.

Competing interests: None declared.

\title{
Half full or half empty VATS?
}

\author{
Peter McCulloch
}

Nuffield

Department of

Surgery, University

of Oxford, John

Radcliffe Hospital,

Oxford OX3 9DU

Peter McCulloch

reader in surgery

Correspondence to:

$\mathrm{P}$ McCulloch

petermcculloch@

doctors.org.uk
These paired studies on video assisted thoracic surgery (VATS) highlight a challenging question for proponents of evidence based medicine. ${ }^{2}$ After 10 years and, in this case, 12 randomised trials, why is practice so variable in specialties where the evidence seems clear? Is evidence based medicine, in fact, ineffective in changing clinical practice?

Disillusion is the child of overoptimism, and we should reflect that many influences for good remain of value despite less than universal adoption. Neither the United Nations nor the European Union has fulfilled all the ideals of their founders, but only their fanatical opponents would deny them some major achievements. Unsystematic review of recent medical progress makes a reasonably convincing case that evidence based medicine also has things to be proud of. Compared with 10 years ago, policy decisions in national health care in Europe and the United States are now informed much less by expert consensus conferences and much more by systematic reviews of the evidence. Medical journals publish more randomised trials, systematic reviews, and meta-analyses than they used to and require a higher degree of rigour in conducting and reporting studies, so the average quality of published medical research has gone up. Clinicians generally are now much more aware of principles of evidence based medicine and demonstrate this through typical guilt responses when they are forced to reveal their non-evidence based practices publicly. Guilt is said to be the first step on the road to redemption, so clinical practice too may be changing for the better.

Another important reflection is that evidence never was and never will be the whole story in medical decision making. Local resources, costs, and, particularly in the case of surgical techniques such as VATS, training needs are among the many practical and organisational barriers to changing established treatments. The systematic review reports that experience with VATS did not correlate with the proportion of eligible cases performed by VATS. This suggests that some units choose to use the technique selectively, but it might also mean that some surgeons never achieve comfort with it and abandon it after a trial period. An extensive psychological and sociological literature points to barriers to change erected by the minds of individuals
Ethical approval: Not required.

1 Lewis RJ, Caccavale RJ, Sisler GE, Mackenzie JW. One hundred consecutive patients undergoing video-assisted thoracic operations. Ann Thorac Surg 1992;54:421-6.

2 Wennberg JE. Understanding geographic variations in health care delivery. N Engl J Med 1999;340:52-3.

Detsky AS. Regional variation in medical care. $N$ Engl J Med 1995;333:589-90.

4 Laycock WS, Siewers AE, Birkmeyer CM, Wennberg DE, Birkmeyer JD. Variation in the use of laparoscopic cholecystectomy for elderly patients with acute cholecystitis. Arch Surg 2000;135:457-62.

5 Sedrakyan A, van der Meulen J, Lewsey J, Treasure T. Video assisted thoracic surgery for treatment of pneumothorax and lung resections: systematic review of randomised clinical trials. BMJ 2004;329:

(Accepted 30 September 2004) and by the shared values and traditions of groups. ${ }^{34}$ Evidence is only one lever in the process of bringing about change, and it needs to be applied at the right point and in the right way in an organisation to be effective. This does not mean that we should give up on it, but that in our quest for quality improvements in health care we should also start to look much more seriously at how change is effectively achieved in organisations. G K Chesterton, a devout Catholic, once described Christianity as having: "not been tried and found wanting; it has been found difficult and left untried." While I would hope that the same fate does not ultimately befall evidence based medicine, the evidence so far does not convince me that it won't.

Competing interests: None declared.

1 Sedrakyan A, van der Meulen J, Lewsey J, Treasure T. Video assisted thoracic surgery for treatment of pneumothorax and lung resections: systematic review of randomised clinical trials. BMJ 2004;329:

2 Sedrakyan A, van der Meulen J, Lewsey J, Treasure T. Variation in use of video assisted thoracic surgery in the United Kingdom. BMJ 2004;329:

3 Plous S. The psychology of judgement and decision making. New York: McGraw-Hill, 1993.

4 Timmermans S, Berg M. The gold standard: the challenge of evidence-based medicine and standardization in health care. Philadelphia: Temple University Press, 2003.

5 Chesterton, GK. What's wrong with the world. New York: Dodd, Mead, 1910.

(Accepted 28 September 2004)

\section{Correction}

Are written responses to some referrals to a general haematology clinic acceptable?

We inadvertently transposed elements of the title of a paper by Tso and colleagues (23 October, pp 946-7), which changed the meaning entirely, after the authors had seen the proofs. The study considered whether written referrals from a haematology clinic were acceptable to general practitioners and patients, not whether they were acceptable to the haematology clinic (as implied by the originally printed title, "Acceptability to a general haematology clinic of written responses to referrals"). The correct title is "Are written responses to some referrals to a general haematology clinic acceptable?" We have corrected this on bmj.com. 